\title{
Avoidance learning and failure to learn in two strains of rats selectively bred for emotionality'
}

\author{
J. M. Joffe \\ INSTITUTE OF PSYCHIATRY, UNIVERSITY OF LONDON
}

\begin{abstract}
Fifteen reactive and 15 non-reactive female rats were trained for 14 days (336 to 428 trials) on an escapeavoidance response in a shuttle box. The reactive group performed fewer avoidance responses, and contained a far greater proportion of animals which failed to learn the response or to respond at a reasonably high rate.
\end{abstract} Introduetion

D'Amato \& Schiff (1963) report the failure of at least half their albino rats in a series of three experiments to learn a simple discriminated avoidance task, although for some Ss the training trials totalled 7,330 over a four-month period. After ruling out a number of other possible explanations of the failure to learn, they conclude that "the explanation that seems most reasonable to us is that the CS, through its association with shock, comes to be a powerful suppressor of behavior, its onset evoking in $\mathrm{S}$ a posture of crouching and freezing that effectively inhibits a wide range of instrumental behavior.' A similar explanation has been advanced by Broadhurst \& Levine (1963) to account for the inferiority of emotionally reactive rats in avoidance learning, a finding which they obtained in two experiments (Broadhurst \& Levine, 1963; Levine \& Broadhurst, 1963) and which is also reported by Owen (1963). In all cases the rats used were from the two Maudsley strains, selectively bred for high and low open field emotionality scores respectively (Broadhurst, 1960, 1962). Broadhurst \& Levine suggest that emotionality would tend to inhibit the motor response required, to the greater disadvantage of reactive Ss in an aavoidance learning situation. The work of Singh (1959, 1960; Singh \& Eysenck, 1960), also with the Maudsley strains, supports this point of view. Investigating the conditioned emotional response in the two strains, Singh found that reactive Ss showed greater decrement of an instrumental bar pressing response in a Skinner box upon presentation of a shock-associated CS. Learning differences between the two Maudsley strains cannot be accounted for in terms of possible inadvertent selection for "intelligence" as Das \& Broadhurst (1959) have shown that the strains do not differ significantly in Hebb-Williams apparatus scores.

All these results indirectly support the conclusion of D'Amato and Schiff, but they might be held to show differences in rate of acquisition rather than a failure to learn to avoid the UCS, since Ss were tested for 90 trials most. Consequently the data from an experiment using long term avoidance training have been analysed in terms of failure to learn, with the expectation that if the D'Amato and Schiff postulation is correct, a significantly greater number of reactive than non-reactive rats will fail to learn an avoidance response.

\section{Subjeets}

Fifteen females from the 23rd generation of each of the Maudsley strains of rats were used. The selection, characteristics, and standard maintenance of the strains is fully described elsewhere (Broadhurst, 1960, 1962; Eysenck \& Broadhurst, 1964). The reactives (MR) in the present experiment defecated significantly more and ambulated significantly less than the non-reactives (MNR) when tested in the standard manner (Broadhurst, 1960) on the open field when they were between 105 and 124 days old. At the start of avoidance training between 11 and 17 days later they were between 117 and 141 days old (mean 128.5, SD 7.62).

\section{Apparatus}

An automatic shuttle box similar to that described by Levine \& England (1960) was used. It differed from theirs in that it contained a center partition incorporating a perspex gate (4 1/2 in by 4 in) which could be locked or unlocked from outside the box by the experimenter. This use of the gate is irrelevant to the present experiment, but was used in training.

\section{Procedure}

The CS was a light of $20 \mathrm{ftc}$. (measured 1 in from the bulb using an Avo model 2 meter) and the UCS shock of $0.3 \mathrm{ma}$. The CS lasted for $4 \mathrm{sec}$. and was followed by shock which terminated with the animal's crossing to the opposite compartment or after $2 \mathrm{sec}$. (phase 1) or $3 \mathrm{sec}$. (phase 2) in the event of a failure to cross. A crossing within $4 \mathrm{sec}$. of the onset of the CS terminated the CS and enabled $S$ to avoid the shock. The intertrial interval averaged $60 \mathrm{sec}$. with a range of $45-74$ sec., randomly presented. The Ss were each run for at least 24 trials daily for 14 days. Some Ss were run for extra trials and an extra session on days $11,12,13$ and 14 if they failed to reach a gradually rising criterion of avoidance $(81 / 2$, $162 / 3,25$ and $331 / 3 \%$ avoiding respectively) on these days, and consequently the total number of trials ranged from 336 to 428 . The training fell into two phases: (1) Days 1, 2 and 3: the center gate was locked and the CS followed by unavoidable and inescapable shock on 18 of the 24 trials, while on six trials, randomly determined, no shock followed the CS. (2) Days 4 to 14: the gate was unlocked and $\mathrm{S}$ could avoid or escape the shock on all trials.

The total number of avoidance responses possible was 264 to 356 .

\section{Results}

As expected, non-reactive Ss were clearly superior to 
reactives, averaging $69.8 \%$ avoidance responses on trials when avoidance was possible to the reactive S's $21.2 \%$.

To compare the numbers of animals from each strain which could be considered to have failed to learn, a Mann-Whitney U-test was used to compare the distribution of scores of each group. This revealed that there were significantly more low scorers amongst the reactive animals $(\mathrm{U}=13 ; \mathrm{P}<.001)$.

To demonstrate that the difference cannot be due to variations only in the rate of learning of the two strains, the percentage avoidance scores of each $\mathrm{S}$ for the last three days of training were subjected to a similar analysis and a significant difference in favor of nonreactive rats was again found $(\mathrm{U}=12.5 ; \mathrm{P}<.001)$. Eight of the 15 reactive animals had failed to reach a $25 \%$ rate of avoiding over the last three days of training, whereas only one non-reactive animal was achieving less than $50 \%$ avoidances. The three animals which can be said to have completely failed to learn (less than $5 \%$ avoiding over the last three days) were all reactives.

\section{Discussion}

The procedures of the present experiment differ in many ways from those of D'Amato and Schiff, but possess the essential similarity of constituting a lengthy avoidance training situation. The failure of some subjects to acquire an apparently simple avoidance response is found in both studies. In the present experiment it was found that the failure to reach a reasonable level (25\%) of avoidance responding or complete failure to learn (less than 5\% avoiding) is significantly related to the emotional constitution of the Ss, and the explanation of the failure to learn advanced by D'Amato and Schiff receives experimental support.

\section{References}

BROADHURST, P. L. Experiments in psychogenetics: applications of biometrical genetics to the inheritance of behavior. In H. J. Eysenck (Ed.) Experiments in personality. Vol. 1. Psychogenetics and psychophar- macology. London: Routledge and Kegan Paul, 1960. Pp. 1-102.

BROADHURST, P. L. A note on further progress in a psychogenetic selection experiment. Psychol.Rep., 1962, 10, 65-66.

BROADHURST, P. L., \& LEVINE, S. Behavioral consistency in strains of rats selectively bred for emotional elimination. Brit. J. Psychol., 1963, 54, 121-125.

D'AMATO, M. R., \& SCHIFF, D. Long-term discriminated avoidance performance in the rat. J. comp. physiol. Psychol., 1964, 57, 123-126.

DAS, G., \& BROADHURST, P. L. The effect of inherited differences in emotional reactivity on a measure of intelligence in the rat. J. comp. physiol. Psychol., 1959, 52, 300-303.

EYSENCK, H. J., \& BROADHURST, P. L. Introduction to Part II of H. J. Eysenck (Ed.), Experiments in motivation. London: Pergamon Press, 1964. Pp. 285-291.

LEVINE, S., \& ENGLAND, S. J. Temporal factors in avoidance learning. J. comp. physiol. Psychol., 1960, 53, 282-283.

LEVINE, S., \& BROADHURST, P. L. Genetic and ontogenetic determinants of adult behavior in the rat. J. comp. physiol. Psychol., 1963, 56, 423-428.

OWEN, S. The effect on avoidance response extinction in rats of CS continuation and emotional constitution. J. genet. Psychol., 1963, 103, 147-151.

SINGH, S. D. Conditioned emotional response in the rat. I. Constitutional and situational determinants. J. comp. physiol. Psychol., 1959, 52, 574-578.

SINGH, S. D. Conditioned emotional response in the rat: effects of stimulant and depressant drugs.J. psychol. Res., 1961, 5, 1-11.

SINGH, S. D., \& EYSENCK, H. J. Conditioned emotional response in the rat. III. Drug antagonism. J.gen. Psychol., 1960, 63, 275-285.

\section{Note}

1. Supported by a grant (RF 113) from the Maudsley and Bethlem Royal Hospitals Research Fund. 